\title{
GRUPO GINÁSTICO UNICAMP: 22 ANOS DE GINÁSTICA GERAL
}

Débora Jucá Lacerda, Universidade Estadual de Campinas - UNICAMP, Campinas,São

Paulo - Brasil

Marco Antonio Coelho Bortoleto, Universidade Estadual de Campinas - UNICAMP, Campinas,São Paulo - Brasil

Elizabeth Paoliello, Universidade Estadual de Campinas - UNICAMP, Campinas, São Paulo

- Brasil

\section{RESUMO}

Há mais de vinte anos, o Grupo Ginástico Unicamp (GGU) vem difundindo sua proposta de Ginástica Geral (GG), integrando conhecimentos das ginásticas esportivas (Artística, Rítmica e Acrobática, etc.), bem como de outras práticas corporais (teatro, circo, dança). Desde 1989, ano de sua criação, o GGU tem instigado a prática da ginástica pautada na criatividade, no prazer e na inclusão, enfocando os valores humanos e o trabalho coletivo. Para além de um grupo de prática da GG, este grupo representa um espaço de formação humana e profissional que, por meio de apresentações, oficinas e cursos, sociabiliza a produção acadêmica do Grupo de Pesquisa em Ginástica da FEF-Unicamp (GPG). Neste contexto, o presente trabalho trata de descrever parte da trajetória histórica deste grupo, destacando as diversas gerações de integrantes, as principais viagens e conquistas, além de outros fatos marcantes. Para isso, foi realizada uma pesquisa documental, combinada com entrevistas a ex-integrantes, integrantes, ex-coordenadores e coordenadores. O resultado desta análise foi organizado cronologicamente em cinco grandes períodos, os quais em seu conjunto revelam a construção de uma grande família de apaixonados pela ginástica, e não apenas de um grupo universitário de GG.

Palavras-Chave: História; Ginástica Geral; Grupo Ginástico Unicamp.

\section{UNICAMP GYMNASTICS GROUP: 22 YEARS OF GENERAL GYMNASTICS}

\begin{abstract}
For over twenty years, the Unicamp Gymnastics Group (GGU) has been spreading its proposal of General Gymnastics (GG) integrating knowledge of the Artistic, Rhythmic and Acrobatic gymnastics, as well as other corporal practices as theater, circus and dance. Since 1989, the year of its creation, GGU has instigated the practice of gymnastics based on creativity, pleasure and inclusion, focusing on human values and collective work. Besides being a group of GG practice, it represents an area of human and professional education, which through presentations, workshops and courses socializes the academic production of the Research Group in Gymnastics from FEF-Unicamp. In this context, this work describes part of the historical trajectory of this group, highlighting the several members' generations, the main trips and achievements, besides other important aspects. A documentary research has been done, combined with interviews with former and current members, former and current coordinators. The results of this analysis were sorted into five major periods, which together


reveal the building, not only of a simple GG university group, but of a large passionate family for gymnastics.

Key-Words: History; General Gymnastics; Unicamp Gymnastics Group.

\section{GRUPO GIMNÁSTICO UNICAMP: 22 AÑOS DE GIMNASIA GENERAL}

\section{RESUMEN}

Desde hace más de veinte años, el Grupo Gimnástico Unicamp (GGU) viene difundiendo su propuesta de Gimnasia General (GG) haciendo la integración del conocimiento de las gimnasias deportivas (artística, rítmica, acrobática, ...), y también del otras práticas corporales (teatro, circo, danza). Desde 1989, el año de su creación, el GGU tiene desarrollado la práctica de la gimnasia basada en la creatividad, en el placer y en la inclusión, centrándose en los valores humanos y en el trabajo colectivo. Además de un grupo de práctica de la GG, consiste en un espacio de formación humana y profesional, que, por medio de presentaciones, talleres e intercambios, sociabiliza la producción académica del Grupo de Investigación en Gimnasia. En este contexto, el presente trabajo tiene como objetivo describir parte de la trayectoria histórica del grupo, destacando sus integrantes, en sus diversas generaciones, los viajes, los principales logros y otros hitos importantes. Para eso, se realizó una investigación documental, juntamente con entrevistas a ex-integrantes, integrantes, ex-coordinadores y coordinadores. Los resultados fueron organizados en cinco grandes períodos, que en su conjunto revelan la construcción de una gran familia de apasionados por la gimnasia, más que un grupo gimnástico universitario de GG.

Palabras-Clave: Historia; Gimnasia General; Grupo Gimnástico Unicamp. 


\section{INTRODUÇÃO}

Criado em 1989 como projeto de pesquisa e extensão da Faculdade de Educação Física (FEF) da Universidade Estadual de Campinas (Unicamp), o Grupo Ginástico Unicamp (GGU) tem por objetivo pesquisar e socializar a prática da Ginástica Geral (GG) - Ginástica para Todos (GPT) -, tendo ao longo de sua história desenvolvido e consolidado uma proposta pedagógica própria, conforme relatam Perez Gallardo e Souza. ${ }^{1} \mathrm{O}$ grupo é composto fundamentalmente por estudantes universitários e professores de educação física (EF), os quais, no decorrer do tempo e conforme suas possibilidades, contribuem para a manutenção do grupo, apesar da constante rotatividade dos integrantes.

Como pesquisa histórica, este trabalho preocupou-se em revelar parte da trajetória do Grupo Ginástico Unicamp, bem como discutir brevemente o impacto sobre a prática da GG em escolas, universidades, associações comunitárias, congressos e eventos da área.

Devido às frequentes mudanças de seus componentes, bem como de seus coordenadores, é possível pensar o GGU em diferentes momentos, embora haja um fio condutor modelado por uma proposta teórico-pedagógica sólida e pelo respaldo do Grupo de Pesquisa em Ginástica da FEF-Unicamp (GPG). Dessa forma, os acontecimentos de cada um destes momentos vão, em seu conjunto, transformando-se na história do Grupo, edificando a memória deste coletivo, registrada nas lembranças de seus integrantes e em documentos que de algum modo registram a atividade do GGU. Eis aqui a importância da organização desta memória, ressaltando os principais fatos que a compuseram, seja por meio dos depoimentos de seus participantes, seja por meio de registros documentais.

Logo, a importância deste trabalho passa pela possibilidade daqueles que já fizeram parte do grupo - ou que a ele ainda pertencem - de recordarem parte de sua experiência, oportunizarem o conhecimento da proposta pedagógica do grupo àqueles que desejam, e, finalmente, tornarem-se um instrumento de resgate do papel que o GGU assumiu, ao longo de sua história, no fomento e difusão da GG como possibilidade gímnica para a formação humana e profissional. 
Considerando os inúmeros aspectos que poderiam ser analisados, este trabalho enfatiza as viagens-turnês (nacionais e internacionais) por meio das quais o GGU vem mostrando diferentes maneiras de praticar, aprender e vivenciar a GG em diversos contextos socioculturais.

Por último, vale ressaltar que, visando sistematizar e facilitar o entendimento desta trajetória histórica, optou-se por descrevê-la em períodos, análogos aos do desenvolvimento humano* .

\section{METODOLOGIA}

Esta pesquisa consiste numa análise documental dos arquivos do acervo do próprio GGU, disponível na sala do Grupo de Pesquisa em Ginástica da FEF-Unicamp, que incluem cartas pessoais, relatórios, arquivos públicos, fotografias, gravações em vídeo (DVD), regulamentos de eventos, recortes de jornais, revistas e e-mails. Livros, teses, comunicações em anais de congressos e artigos acadêmicos complementaram o referencial teórico analisado nesta pesquisa.

Os documentos foram analisados seguindo as etapas relatadas por Gil. ${ }^{2}$ Deste modo, foi realizada uma pré-análise documental, ou seja, a seleção dos documentos mais interessantes e importantes para a pesquisa, seguida da exploração e análise do material e da interpretação dos dados.

As fotografias foram parte importante dos documentos analisados nesta pesquisa, uma vez que registram e revelam, de modo ímpar, elementos fundamentais da história do GGU (viagens, pessoas, lugares, materiais, figurinos, etc.). A maior parte das imagens analisadas pertence ao acervo do GGU, embora também tenham sido consultados os acervo pessoais de alguns dos integrantes.

Outra fonte de dados foram os depoimentos de membros atuais e ex-membros do GGU, a partir de entrevistas que visaram registrar as impressões e experiências de alguns dos protagonistas desta história. Este tipo de relato, assim como os realizados a partir do método de história oral,

\footnotetext{
* Inspirados na obra de Jorge Sergio Pérez Gallardo (Org.). intitulada "Educação Física escolar: do berçário ao ensino médio". Rio de Janeiro: Lucerna, 2003.

Conexões: revista da Faculdade de Educação Física da UNICAMP, Campinas, v. 10, n. Especial, p. 192-208, dez. 2012.195 ISSN: 1983-9030
} 
privilegia a realização de entrevistas com pessoas que participaram de, ou testemunharam acontecimentos, conjunturas, visões de mundo, como forma de se aproximar do objetivo de estudo. Como consequência, o método da história oral produz fontes de consulta (as entrevistas) para outros estudos, podendo ser reunidas em um acervo aberto a pesquisadores. Trata-se de estudar acontecimentos históricos, instituições, grupos sociais, categorias profissionais, movimentos, conjunturas, etc., à luz de depoimentos de pessoas que deles participaram ou testemunharam. ${ }^{3}$

As entrevistas foram realizadas com base nos procedimentos relatados por Alberti, ${ }^{3}$ buscando complementar, ampliar e contrastar as informações reveladas pelos documentos. Dessa forma, dois procedimentos-instrumentos (pesquisa documental e entrevistas) configuraram a pesquisa. Tratou-se, assim, de estabelecer um "diálogo entre entrevistado e entrevistadores para construção e interpretação do passado atualizada através da linguagem falada", 3 entendendo a necessidade do envolvimento de membros e ex-membros do GGU como sujeitos da pesquisa.

A escolha dos entrevistados aconteceu levando-se em conta o papel estratégico dos sujeitos no grupo, partindo de uma listagem ampla e provisória, elaborada no início do projeto, até chegar aos sujeitos entrevistados. A princípio, pensou-se em entrevistar todos os ex-coordenadores, bem como os atuais, além de um integrante de cada época, isto é, em um período de cinco em cinco anos. Porém, isso não foi necessário pela facilidade de acesso a depoimentos em DVDs e outros documentos do acervo, os quais se tornaram fonte de dados significativa para o trabalho. Assim, pois, foram entrevistados dois coordenadores e dois integrantes, a saber: Jorge Sergio Pérez Gallardo (coordenador do período de 1992 a 2003), Eliana de Toledo (integrante no período de 1991 a 2005 e coordenadora entre 2005 e 2006), Andréi Parmezan (integrante na década de 1990 e pioneiro no programa de intercâmbio com a Dinamarca) e Helaine Lima (integrante desde 2003). É importante mencionar que os entrevistados também foram escolhidos devido à sua disponibilidade, proximidade geográfica e principalmente pelo profundo vínculo estabelecido com o grupo.

As entrevistas foram registradas por meio de um gravador de voz digital, sendo transcritas e analisadas a posteriori. Para a análise, foi empregado o método de Análise de Conteúdo, conforme as indicações de Bardin. ${ }^{4}$

\section{GRUPO GINÁSTICO UNICAMP 1989: O NASCIMENTO}

Conexões: revista da Faculdade de Educação Física da UNICAMP, Campinas, v. 10, n. Especial, p. 192-208, dez. 2012.196 ISSN: 1983-9030 
Naquele ano, 1989, as docentes da Faculdade de Educação Física da Unicamp Elizabeth Paoliello Machado de Souza e Vilma Leni Nista-Piccolo decidiram se reunir para dar início a um novo projeto, o Grupo Ginástico Unicamp, cujo propósito foi descrito da seguinte forma:

\begin{abstract}
Este grupo foi criado com a intenção de abrir um espaço para a concretização de estudos exploratórios do movimento corporal. O resultado desses estudos gera pesquisas no campo da Motricidade Humana, contribuindo assim de forma relevante para o desenvolvimento científico do país. Busca-se uma integração de modalidade da área da Ginástica, ou seja, o encontro dos elementos ginásticos e acrobáticos da Ginástica Artística com a suavidade e a expressão da dança, associados ao ritmo e à destreza do manejo dos aparelhos de Ginástica Rítmica Desportiva. O que se propõe é uma forma alternativa de utilização dos fundamentos desses esportes, com exploração de novas possibilidades de movimento criando-se oportunidade de maior divulgação da Ginástica Geral no Brasil. ${ }^{5}$
\end{abstract}

Os ideais do Grupo, naquela época e até hoje, consideram a importância do crescimento da Educação Física por meio de pesquisas que aproximem a teoria da prática, especialmente no âmbito pedagógico. Logo, a proposta central continha diferentes valores relativos à formação humana, fundamentais para a preparação dos profissionais da área.

Elizabeth Paoliello e Vilma Leni Nista-Piccolo, além de professoras da FEF-Unicamp e responsáveis pelas disciplinas da área da Ginástica, já haviam trabalhado juntas em outras instituições de ensino e num clube da cidade de Campinas, SP, onde acumularam experiências na área da ginástica na condição de treinadoras de equipes competitivas nas modalidades Ginástica Rítmica (GR) e Ginástica Artística (GA), respectivamente.

Dessa forma, surgiu a proposta de criação do Grupo Ginástico Unicamp, que buscava a integração dos conhecimentos das distintas modalidades ginásticas com a dança, porém sem a conotação competitiva. O projeto tinha ainda como metas a ampliação das pesquisas na área e a difusão da prática da ginástica, mais especificamente da Ginástica Geral, nos diferentes setores da sociedade embasados nos conhecimentos acadêmicos.

Para a criação do Grupo Ginástico Unicamp, 12 ginastas e 6 bailarinas foram convidadas pelas coordenadoras para fazer parte do grupo, que tinha como objetivo imediato participar da VI Gimnasiada Americana em Buenos Aires. Na sua maioria, tinham sido ginastas ou alunas das referidas professoras, algumas com grande destaque no âmbito esportivo, tendo 
participado de conquistas que levaram Campinas a ser conhecida como a "Capital de Ginástica" durante mais de uma década. Esta foi a primeira geração do GGU.

O grupo iniciou seu repertório coreográfico com a composição Guaicá, coreografia elaborada no mês de julho de 1989 cujos treinos oficiais foram iniciados no dia 2 de agosto, às quartasfeiras, entre as 20 e as 22 horas, e aos sábados entre as 08 h30min e as $12 \mathrm{~h} 30 \mathrm{~min}$, além de treinos extras em período próximo ao das apresentações. A Guaicá foi elaborada com a participação das integrantes do grupo contando com 8 minutos de duração e tendo como conteúdo a integração de elementos da GA e da GR com movimentos e ritmos da cultura brasileira.

A primeira apresentação oficial do GGU aconteceu no Festival SESC Móbil de Ginástica e Dança no dia 14 de setembro de 1989 com a coreografia Guaicá. Já a primeira viagem internacional foi em outubro do mesmo ano para Buenos Aires, Argentina, onde foi realizada a VI Gimnasiada Americana, evento que tinha como objetivo principal fomentar o intercâmbio científico-tecnológico, sociocultural e educativo da Educação Física e Esporte nas Américas. O GGU teve grande destaque e aceitação, tendo sido convidado para participar da noite de gala do evento, o que motivou enormemente a sua continuidade.

\section{GGU 1990 a 1995: A Primeira Infância}

Após o retorno de Buenos Aires, o GGU retomou os treinamentos e aos poucos incorporou novos integrantes, incluindo os primeiros homens, cujo trabalho resultou numa nova coreografia, intitulada Lambachiana, com 7 minutos de duração.

Dentre as participações do grupo, neste período se pode destacar o $9^{\circ}$ Fegin - Festival Nacional de Ginástica, em Ouro Preto, MG. Este festival teve grande importância para a história da GG, pois foi o primeiro festival nacional na área, reunindo grupos de todo o País. A participação do GGU foi um incentivo para produzir um material de qualidade para a divulgação do trabalho do grupo, com o objetivo de conseguir patrocínio para a $9^{\text {a }}$ Gymnaestrada Mundial, que aconteceria no ano seguinte. Durante o Fegin, foram credenciados os grupos interessados em integrar a delegação brasileira no referido evento. 
A 9 $9^{a}$ Gymnaestrada Mundial foi realizada em Amsterdam, entre os dias 14 e 20 de julho de 2001. O GGU embarcou com 16 ginastas, sendo 2 homens e 14 mulheres, juntamente com a coordenadora Elizabeth Paoliello, pois a professora Vilma Piccolo não pôde viajar com o grupo.

Houve um total de 19.500 ginastas de 28 países presentes na $9^{\text {a }}$ Gymnaestrada Mundial, sendo apenas o Brasil e o Canadá os países participantes do Continente Americano. Este evento, considerado o mais importante da área, representa um encontro entre dezenas de nações que se unem para confraternizar a prática da ginástica por meio de apresentações, discussões, troca de informações e ideias, sem o objetivo da competição. Em outras palavras,

É a manifestação mundial oficial da ginástica geral organizada pela FIG a cada quatro anos e caracteriza-se como a atividade mais significativa dessa instituição no campo da GG. Isso permite afirmar, sem exagero, que a ginástica geral tem sido para a FIG sinônimo de "World Gymnaestrada", uma vez que praticamente todas as suas ações na área da GG continuam voltando-se, quase que exclusivamente, para a promoção desse evento. ${ }^{6}$

Souza $^{5}$ descreve um pouco dos sentimentos dos participantes nesta Gymnaestrada da seguinte forma:

Nesta festa mundial da Ginástica, as pessoas buscavam a integração numa troca constante de experiências, expressas na tentativa de comunicação em línguas diferentes, no cantar as músicas de outros países, no dançar as danças típicas, na troca literal de camisetas, uniformes e 'souvenirs'. Para os participantes, o mundo tornou-se pequeno durante este evento. As culturas se entrelaçaram, as pessoas se conheceram e a Ginástica foi o vínculo que proporcionou esta inesquecível experiência àqueles que lá estiveram. Esta vivência internacional fortaleceu e motivou o nosso grupo na busca de novas propostas.

Certamente esta experiência influenciou os novos projetos do GGU.

Após o afastamento da professora Vilma Leni Nista-Piccolo da coordenação, em 2002, a professora Elizabeth Paoliello convidou o professor Jorge Sergio Pérez Gallardo para compartilhar da coordenação do grupo.

Ex-integrante do Ballet Folclórico Nacional do Chile, fundador e diretor do Curso de Pedagogia em Educação Física na Universidade do Chile e responsável pelo Grupo de Ginástica Rítmica Formativa no mesmo país, a maior contribuição de Pérez para o GGU foi, 
seguramente, a implementação da uma proposta pedagógica cujos princípios embasam até nossos dias a atividade do GGU. ${ }^{1}$ Com ela, o Grupo Ginástico busca novas formas de desenvolver a Educação Física e particularmente a Ginástica em diferentes espaços educativos, principalmente nas escolas e na comunidade. Nesta proposta, o indivíduo é valorizado independentemente de suas características e capacidades físicas ou técnicas, contribuindo com sua experiência para o grupo. As composições coreográficas são elaboradas coletivamente e valorizam a diversidade cultural e a interação social. Chaparim ${ }^{7}$ expõe o seu ponto de vista com relação à proposta da seguinte maneira:

Pela proposta pedagógica do GGU, os praticantes integram atividades grupais que tenham relações com as suas necessidades, características, expectativas, privilegiando elementos culturais com base em valores humanos, tais como cooperação, responsabilidades autoestima e respeito pelo outro. Os praticantes são incentivados a desenvolver suas qualidades, explorar e descobrir seus potenciais com criatividade. O respeito pelas características individuais aumenta o interesse pelas atividades e a interação social.

Os princípios que norteiam a proposta do GGU são a formação e a capacitação humana, conforme as diretrizes expressas na obra de Maturana e Rezepka. ${ }^{8}$ Nas palavras de Jorge Pérez Gallardo, em sua entrevista, a proposta tem caráter cooperativo: "você faz com todo potencial que você tem; se não tem muito, o grupo aceita. [...] $\mathrm{O}$ grupo te permite fazer alguma coisa, ao mesmo tempo em que você tem que permitir outra, tem que conversar, tem que dialogar, tem que discutir, coisa que não acontece em uma composição (coreográfica) feita por uma pessoa, como por um técnico - o melhor de cada um deve ser colocado a serviço do grupo, explorando o potencial que cada um tem”.

Deste modo, o GGU segue um modelo democrático, uma vez que os integrantes participam dando opiniões, sugestões e da discussão de todos os passos que compõem a prática cotidiana da GG, incluindo escolha dos movimentos, música, figurino, temas das coreografias e aparelhos, entre outros aspectos fundamentais do processo criativo e da posterior socialização (apresentações).

Em outubro de 1993, o Grupo Ginástico Unicamp teve a grande oportunidade de divulgar seus trabalhos e pesquisas no Chile por meio de apresentações, cursos e palestras. Participaram 21 ginastas em 14 dias de viagem, quando, de acordo com o relatório técnico da viagem retirado do acervo do grupo, o GGU “mostrou a importância da utilização da cultura 
corporal dos alunos para desenvolver seu domínio corporal através de atividades e implementos próprios de sua cultura, contribuindo desta forma com o compromisso de socialização da escola”.

Em 1994, aconteceu o primeiro contato com os escandinavos, momento em que o grupo dinamarquês Danish Gym-Team Holstebro-Lemvigegnens veio para uma turnê no Chile e no Brasil promovida pela Associação Dinamarquesa de Ginástica e Esportes (Danske Gymnastik \& Idrætsforeninger - DGI), uma organização que trabalha por meio do esporte e outras atividades culturais para fortalecer o trabalho voluntário e promover a participação popular e o Esporte para Todos. O grupo foi recebido na FEF-Unicamp, onde realizou juntamente com o GGU apresentação e curso para os estudantes, dando início a um forte vínculo que ainda hoje perdura com inúmeros projetos cooperativos.

A equipe dinamarquesa, coordenada por Holger Vestergaard, veio com ginastas na idade entre 18 e 30 anos e um programa com 21 apresentações da tradicional ginástica da Dinamarca. Holger foi o grande incentivador e facilitador dos intercâmbios internacionais do GGU, especialmente com a Dinamarca, abrindo portas e dando início à participação internacional do GGU.

O primeiro contato com os dinamarqueses, em 1994, rendeu dois convites que iniciariam a turnê do grupo por três países europeus: Espanha (International Gymnastic Festival, em Alicante), Dinamarca (esta foi a primeira vez que os integrantes do GGU estiveram no País, estreitando as relações entre o Brasil e a Dinamarca) e Alemanha (X Gymnaestrada Mundial, em Berlim). A princípio, o Grupo se preparava apenas para a sua segunda participação na Gymnaestrada Mundial, mas a viagem foi estendida devido aos demais convites surpreendentes.

Nestes eventos, o GGU apresentou-se em aberturas, ofereceu cursos de ginástica e danças brasileiras e representou o Brasil com as coreografias "Batucada", "Cordas Grandes e Pequenas", "Bambu", "Maculelê" e "Soma de Fases Motoras". Além disso, o grupo atuou na Noite de Gala e na Noite Brasileira na Gymnaestrada de Berlin, esta última realizada pela primeira vez numa Gymnaestrada e já com grande sucesso. 


\section{GGU 1996 a 2000: A Segunda Infância}

O GGU participou de um evento muito importante no ano de 1996, o $3^{\circ}$ Congresso LatinoAmericano: Esporte, Educação e Saúde do Movimento Humano ICHPER-SD, em Foz do Iguaçu, que tinha o objetivo de promover a discussão das pesquisas nas áreas da EF. Isso permitiu que apresentasse suas pesquisas sobre a utilização da cultura corporal como uma forma para o desenvolvimento da EF por meio de composições coreográficas de GG.

Participar daquele Congresso em Foz do Iguaçu foi extremamente relevante para o Grupo Ginástico Unicamp pelas experiências profissionais e pela repercussão, que foi além do que era esperado: após o evento, surgiram vários convites para o Grupo ministrar cursos e palestras no Brasil, como, por exemplo, na rede de ensino do estado do Paraná e no Exterior, a saber, no Equador e na Colômbia. Muitos profissionais e instituições (de colégios a universidades) enviaram ao GGU solicitações de assessorias, de vídeos e de material didático em geral (publicações, coreografias e músicas utilizadas no congresso), evidenciando a necessidade de ampliar a produção acadêmica sobre a proposta do grupo.

Neste período, o GGU teve a oportunidade de voltar à Dinamarca - onde apresentou sua nova coreografia "Amazônia" no festival Landsstævne, em Silkborg, que teve a participação de 20.772 ginastas) - assim como à Argentina e ao Chile, realizando diferentes intercâmbios acadêmicos e, com isso, ampliando seus contatos e vínculos institucionais.

Inovando seus destinos, o GGU participou ainda em 1999 da quarta edição do Festival del Sole em Riccione, na Itália, e da XI Gymnaestrada Mundial, que aconteceu na cidade de Göteborg, Suécia.

Como pode ser percebido, as conquistas do GGU ampliaram-se significativamente tanto em âmbito nacional quanto internacional neste período. Logo, as experiências vividas pelo Grupo enriqueceram a sua visão sobre as diversas maneiras de praticar a Ginástica Geral, aumentaram a compreensão dos integrantes a respeito de novas culturas e auxiliaram a criatividade nas composições coreográficas. Além disso, a proposta pedagógica do GGU na área da GG/GPT tornou-se mais conhecida, fomentando novos contatos e parcerias com outras instituições nacionais e internacionais.

\section{GGU 2001 a 2005: A Adolescência}

Conexões: revista da Faculdade de Educação Física da UNICAMP, Campinas, v. 10, n. Especial, p. 192-208, dez. 2012.202 ISSN: 1983-9030 
O ano de 2001 iniciou-se com a participação da reinauguração do SESC-Campinas no dia 8 de abril, evento esse de grande importância para a cidade, contando com a presença de grandes autoridades do esporte, cultura e lazer. O GGU foi convidado para dar oficinas de Ginástica Geral e mostrar a sua proposta no festival de comemoração com as coreografias “Amazônia”, "Pulso Acrobático" e "Túnel”. Essa participação do Grupo reforçou a parceria com o SESC-Campinas, iniciada em 1999 com a realização conjunta do Fórum Brasileiro de Ginástica Geral, e motivou a promoção do Fórum Internacional de Ginástica Geral (FIGG), evento que surgiu como uma proposta do Grupo de Pesquisa em Ginástica da FEF-Unicamp, com apoio internacional da ISCA - International Sport and Culture Association. O evento contou com a participação de cerca de 100 ginastas de várias nações, como a Alemanha, a Argentina, o Brasil, o Chile e a Dinamarca, além de inúmeros grupos brasileiros. Foram ainda realizados cursos, festivais e uma intensa programação científica com conferências, mesas temáticas e sessão de pôsteres.

Além de viagens e apresentações importantes, como o Festival de Alicante (Espanha), o Turnfest de Ginástica, na cidade de Leipzig (Alemanha) e a XII Gymnaestrada Mundial, em Lisboa (Portugal) em 2003, esse período foi marcado por outras duas viagens significativas para o GGU, realizadas no ano de 2004. Referimo-nos ao convite do Instituto Superior de Educación Física (ISEF) Federico Dickens, de Buenos Aires, para participar do "Congreso de Educación Física - Diferentes miradas: comunidad, escuela y salud”, ocasião em que também teve a oportunidade de se apresentar em escolas, clubes e em cinco faculdades de educação física da capital argentina, difundindo sua proposta de Ginástica Geral. Nesse congresso, o GGU fez apresentações, participou de conferências, ofereceu cursos e alguns dos seus 23 integrantes tiveram trabalhos de pesquisa expostos.

No mês seguinte, surgiu outro projeto itinerante como desafio para os integrantes do GGU: a turnê brasileira em parceira com o SESC-Campinas denominada "O Corpo é o Espetáculo", da qual participava também a renomada companhia Ballet Stagium. O Grupo Ginástico apresentou-se em 8 cidades da região de Campinas, SP, com um programa de 1 hora de duração que mostrava a diversidade da GG, com elementos da ginástica, dança, teatro e circo, uma experiência que marcou a trajetória do GGU no ano em que o Grupo completava seus 15 anos. 
Contudo, "as águas de um mesmo rio nunca são as mesmas", e as mudanças também fizeram parte da trajetória do GGU. O professor Jorge Pérez Gallardo deixa a coordenação do grupo após quase 12 anos de dedicação e parceria com a professora Elizabeth Paoliello, e, desta forma, o adolescente GGU passa por mais uma transição. Por conseguinte, no ano de 2005, a professora Elizabeth, ao se aposentar, convidou a professora Eliana de Toledo para coordenar o GGU e assumir aos poucos as responsabilidades desenvolvidas por ela, Elizabeth, desde 1989. Eliana fazia parte do Grupo desde 1991 e assumiu com grande competência e dedicação a coordenação, dando continuidade às atividades regulares. É claro que Jorge e Beth não abandonaram o GGU. E nem seria possível, com tantos anos presentes, ajudando esse grande e influente Grupo a crescer. Eles apenas se afastaram paulatinamente, permitindo uma transição de coordenadores.

\section{GGU 2006 a 2011: A Juventude}

No início de 2006, ao lado de Eliana de Toledo, assume a coordenação do Grupo o professor Marco Antonio Coelho Bortoleto, recém-incorporado ao corpo docente da FEF-Unicamp e também ex-integrante do Grupo. No ano seguinte, Eliana de Toledo deixa a coordenação e em seu lugar assume a professora Larissa Graner, que militava no Grupo havia anos e que permanece nessa função até a presente data, ao lado do referido professor.

Esse ano marca a maioridade do GGU: 18 anos de intensa atividade na área da Ginástica Geral, pelos quais passaram aproximadamente 200 integrantes. O Grupo comemora a data esbanjando vitalidade e com uma bagagem de 12 viagens internacionais, que permitiram visitar diversos países, entre eles a Argentina, a Holanda, o Chile, a Dinamarca, a Espanha, a Alemanha, a Itália, a Suécia e Portugal.

No ano de 2008, o GGU realizou sua $13^{\mathrm{a}}$ turnê internacional, com apoio da ISCA, participando do Festival de Verano, em Bogotá, Colômbia, entre os dias 7 e 18 de agosto. A viagem foi especial para todos os participantes, uma vez que Bogotá celebrava seus 470 anos e convidou o GGU para se apresentar com todas as despesas pagas, incluindo passagens, alojamento e alimentação para 25 pessoas. Pela primeira vez, em todos os anos de experiência do GGU, a viagem teve mais de $70 \%$ dos custos patrocinados. Num esforço conjunto, o GGU conseguiu levar todos os seus 36 integrantes, arcando com a diferença das despesas e 
fortalecendo a união e interação do grupo. Mais um grande passo como Grupo, como um coletivo!

Outro grande marco da história aqui registrada: os 20 anos do Grupo Ginástico Unicamp, comemorados no dia 27 de novembro de 2009 com um grande festival no Ginásio do Taquaral, em Campinas. O "Festival GGU 20 Anos" contou com dois programas: um à tarde, e outro à noite, os quais envolveram diversos grupos e tiveram como público-alvo alunos de escolas públicas de Campinas e região, além de ONGs e do público em geral, somando aproximadamente 2.000 pessoas. Uma festa inteira de ginástica!

Já em 2010, o grupo participou da organização e execução do II Seminário Internacional de Ginástica Artística e Rítmica de Competição (Sigarc), em Campinas, SP. Alguns dias depois, em julho de 2010, o GGU atuou na organização do V Fórum Internacional de Ginástica Geral, apresentando-se em todos os festivais deste evento, que teve como tema central "Cultura da Ginástica: concepções e práticas”. Como sempre, os integrantes do grupo representaram a alma destes eventos por meio de sua atuação voluntária, colocando a FEF-Unicamp, o Grupo de Pesquisa em Ginástica e, por que não, a cidade de Campinas, SP, no centro dos debates sobre a ginástica.

Ainda em 2010, o GGU recebeu a visita de um querido dinamarquês, Svend Noe Thomassen, por cerca de três meses. Dentre os muitos intercâmbios que compuseram essa visita, destacase o Curso Acrobacia sobre a pista inflável - Airtrack, especialmente realizado para os integrantes do GGU. Nos meses de agosto e setembro, o professor dinamarquês - com suporte de alguns membros do grupo - ofereceu uma série de oficinas em escolas e universidades de diversas regiões do Brasil.

Por fim, em 2011 o Grupo teve o privilégio de participar da 14 ${ }^{\mathrm{a}}$ Gymnaestrada Mundial em Lausanne, na Suíça, com um coletivo de 30 ginastas, 2 coordenadores (Marco e Larissa) e 2 acompanhantes, incluindo a Prof. ${ }^{\text {a }}$ Elizabeth. Após 8 dias na Suíça, o GGU realizou sua $14^{\text {a }}$ Turnê Internacional, desta vez pela Dinamarca, com suporte do DGI-FYN, oferecendo cursos, oficinas e realizando apresentações por diferentes cidades, dentre as quais se destacam: Ollerup, Svendborg, Odense, Århus, Viborg e Copenhague durante uma semana. 
Não bastassem os compromissos anteriores e encerrando mais um ciclo, embora a história do grupo não deixe de se atualizar, o GGU participou, também em 2011, do "Festival de 10 Anos" do Grupo Dickens, em Buenos Aires,. Nesta, que foi a $15^{\text {a }}$ Turnê Internacional do Grupo, foram realizadas diversas oficinas a professores daquele país. Ao regressar ao Brasil, o grupo encontrou forças para participar em dezembro, pela primeira vez em sua história, da "Ginástica de Gala", uma apresentação transmitida em rede nacional cuja organização foi de responsabilidade da Confederação Brasileira de Ginástica.

\section{CONSIDERAÇÕES FINAIS}

Como é possível deduzir do relato aqui realizado, o GGU tem sido um espaço de formação para muitos alunos da Unicamp e de outras instituições. Sua participação regularmente em eventos nacionais e internacionais tem servido para difundir a proposta do grupo para diferentes públicos, bem como aprender e renovar sua linguagem gímnica. Consequentemente, muitos de seus integrantes têm levado a GG para as escolas, faculdades, e outras organizações, mantendo um panorama favorável para a difusão e discussão da cultura ginástica. Assim, apesar das dificuldades contemporâneas que incidem sobre a prática da ginástica, o grupo tem contribuído para a renovação da prática educativa da ginástica.

Neste contexto, o GGU proporciona a todos os seus integrantes um espaço de aprendizagem, de fomento da amizade, da prática da ginástica, de capacitação e formação humana. Um verdadeiro laboratório, ou melhor, um banco de ideias, como o próprio grupo prefere denominar, para qualquer interessado na ginástica.

Mesmo sendo um projeto oficial numa universidade pública, o grupo ainda enfrenta dificuldades para sua manutenção, superando-as graças ao empenho de todos, ao voluntariado e ao interesse na prática da ginástica e na possibilidade de um trabalho coletivo e democrático.

Resgatar mais de duas décadas de trajetória histórica do GGU consistiu num grande desafio, especialmente pela imensa quantidade de fatos dos quais apenas uma pequena parte foi relatada nesta oportunidade. Porém, o trabalho foi enormemente facilitado pela organização do material e da documentação do grupo, e pela generosidade de todos que contribuíram para a realização desta pesquisa.

Conexões: revista da Faculdade de Educação Física da UNICAMP, Campinas, v. 10, n. Especial, p. 192-208, dez. 2012. 206 ISSN: 1983-9030 
Finalmente, esta oportunidade permitiu, em suma, reforçar uma frase que frequentemente é ouvida no interior do grupo, isto é, que se trata do GG "Único", um coletivo ginástico fruto da paixão e da coletividade, do afeto e da alegria de fazer ginástica e com ela projetar uma proposta educativa e, portanto, um mundo melhor.

\section{REFERÊNCIAS}

${ }^{1}$ PEREZ GALLARDO, J. S. P.; SOUZA, E. P. M. A proposta de ginástica geral do grupo ginástico UNICAMP. In: PEREZ GALLARDO, J. S. et al. Coletânea: Encontro de Ginástica Geral. Campinas: Gráfica Central da UNICAMP, 1996. p. 25-32, 33-36.

${ }^{2}$ GIL, A. C. Como elaborar um projeto de pesquisa. 4. ed. São Paulo: Atlas, 2002.

${ }^{3}$ ALBERTI, V. Manual da história oral. 3. ed. Rio de Janeiro: FGV, 2005.

${ }^{4}$ BARDIN, L. Análise de conteúdo. Lisboa: Edições 70, 2008.

${ }^{5}$ SOUZA, E. P. M. Ginástica geral: uma área do conhecimento da Educação Física. 1997. 163 f. Tese (Doutorado em Educação Física), Universidade Estadual de Campinas, Faculdade de Educação Física, Campinas, 1997, p. 72.

${ }^{6}$ AYOUB, E. Ginástica geral e Educação Física escolar. 2. ed. Campinas: Ed. da UNICAMP, 2007.

${ }^{7}$ CHAPARIM, F. C. A. S. Ginástica Geral com adolescentes em situação de risco social. In: PAOLIELLO, E. (Org.). Ginástica Geral: experiências e reflexões. São Paulo: Phorte, 2008. p. 79-96.

8 MATURANA, H.; REZEPKA, S. N. Formación humana y capacitación. Santiago: Dólmen, 1995.

9 FÓRUM INTERNACIONAL DE GINÁSTICA GERAL, 1, 2001, Campinas. Anais... Campinas: FEF-Unicamp: SESC, 2001. 
${ }^{10}$ FIORIN-FUGLSANG, C. M.; PAOLIELLO, E. Possíveis relações entre ginástica geral e o lazer. In: PAOLIELLO, E. (Org.). Ginástica geral: experiências e reflexões. São Paulo: Phorte, 2008. p. 97-119.

${ }^{11}$ OLIVEIRA, N. C. de. Ginástica para todos: perspectivas no contexto do lazer. Revista Mackenzie de Educação Física e Esporte, São Paulo, v. 6, n. 1, 2007. 